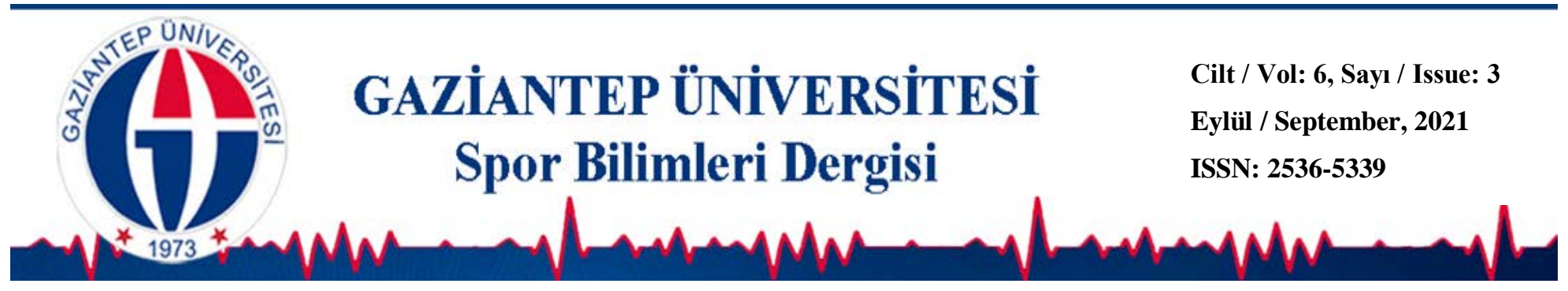

\title{
Sporcularda Kan Akımı Kısıtlamalı Antrenman ve Fizyolojik Mekanizması
}

\author{
Dursun Alper YILMAZ ${ }^{1 *}$ D \\ GÖKHAN DEGE ${ }^{1}$ iD \\ ${ }^{1}$ Ağrı İbrahim Çeçen Üniversitesi, Sağlı Yüksekokulu, $A \breve{G} R I$
}

DOI: 10.31680/gaunjss.948063

Derleme / Review

Geliş Tarihi / Received: 04.06.2021 Kabul Tarihi / Accepted: 02.08.2021 Yayın Tarihi / Published: 20.09.2021

\section{Öz}

İskelet kası kasılması ile kan akımının düzenlenebilmesi bizlere; kas yorgunluğu, kan basınç refleksleri ve metabolizmanın fizyolojik işleyişi hakkında birçok bilgi vermektedir. Kan akımı kısıtlaması (KAK) kullanımına artan ilgi, egzersizin kan akımının azaldığı dönemlerde antrenman uyarlamalarını nasıl etkileyebileceğini açıklığa kavuşturmaya odaklanmaktadır. Bu ilginin esas sebebi, sağlıklı popülasyonlarda değişimi tetiklemesi beklenmeyen oldukça düşük yoğunluklar ve dirençler kullanıldığında bile bireylerin kas boyutunda, kuvvetinde ve dayanıklılık kapasitelerinde artışları gösteren çalışmaların bulunmasıdır. KAK egzersizinin güç ve dayanıklılık çalışan sporcuların antrenmanlarına dâhil edilmesinin, iskelet kası ve kardiyovasküler adaptasyonları artıran fizyolojik faydalar sağladığı gösterilmiştir. Son bulgular, KAK egzersizinin yerel kas oksijen mevcudiyeti ve vasküler kayma stresi gibi akut fizyolojik stres faktörlerini değiştirdiğini ve bunun da geleneksel antrenmanla kolayca elde edilemeyen adaptasyonları sağlayabileceğini göstermektedir. Sporcular için KAK antrenmanının anlaşılmasındaki bir başka mevcut sınırlama ise, mekanizmaya ait bilgilerin çoğunun rekreasyonel olarak aktif veya antrenmansız bireylerden derlenmiş olmasıdır. Antrenman durumu egzersize tepkiyi etkilediğinden, sporcunun KAK egzersizine verdiği tepkinin karakterize edilmesi gereklidir. Bununla birlikte, KAK'ın fizyolojik adaptasyonları nasıl etkilediğini anlamamızı sağlayacak son gelişmeler, KAK egzersizinin iyi hedeflenmiş uyarlamalarını sağlayarak sporcuların fiziksel performanslarının optimizasyonunda kolaylıklar sağlayacaktır. Bu inceleme söz konusu kavramları araştırmakta ve sporcularda KAK antrenmanı uygulamanın etkilerini, kanıta dayalı şekilde özetleyerek bilgi boşluklarını doldurmaktadır

Anahtar Kelimeler: Antrenman, Egzersiz, Fizyoloji, Kan Akımı Kısıtlama,

\section{Blood Flow Restricted Training and Its Physiological Mechanism in Athletes}

\begin{abstract}
The regulation of blood flow by skeletal muscle contraction gives us a lot of information about muscle fatigue, blood pressure reflexes, and the physiological functioning of metabolism. Increasing interest in the use of blood flow restriction (BFR) focuses on clarifying how exercise can affect training adaptations during periods of reduced blood flow. The main reason for this interest is that there are studies showing increases in muscle size, strength and endurance capacity of individuals even when using very low intensities and resistances that are not expected to trigger a change in healthy populations. It has been shown that the inclusion of BFR exercise in the training of athletes working in strength and endurance branches provides physiological benefits that increase skeletal muscle and cardiovascular adaptations. Recent findings suggest that BFR exercise modifies acute physiological stress factors such as local muscle oxygen availability and vascular shear stress, which can provide adaptations not easily achieved with conventional training. Another current limitation to the understanding of BFR training for athletes is that most of the information on the mechanism has been compiled from recreationally active or untrained individuals. Since the training situation influences the response to exercise, it is necessary to characterize the athlete's response to BFR exercise. However, recent developments that will enable us to understand how BFR affects physiological adaptations will facilitate the optimization of the physical performance of athletes by providing well-targeted adaptations of BFR exercise. Based on the evidence, this article explores these concepts and works on filling the gaps by summarizing the effects of BFR training in athletes.
\end{abstract}

Keywords: Blood Flow Restriction, Exercise, Physiology, Training

\footnotetext{
* Sorumlu Yazar: Dursun Alper YILMAZ
}

e-mail: alper96@outlook.com 


\section{Giriş}

Genellikle kan akımı kısıtlama (KAK) egzersizi olarak adlandırılan egzersiz sırasında kan akımının kasıtlı olarak azaltıması işlemi; tipik olarak arteriyel kan akımını azaltmak, venöz çıkışı kısıtlamak veya turnike vasıtasıyla tıkama yoluyla gerçekleştirilir. Çalışmalar; geleneksel olarak sağlıklı popülasyonlarda değişimi teşvik edemediği düşünülen egzersiz modlarını ve yoğunluklarını kullanarak, KAK antrenmanını takiben kuvvet artışı, dayanıklılık ve atletik performans uyarlamaları gözlemlendiğini vurgulamaktadır (Loenneke, Wilson, Marín, Zourdos ve Bemben, 2012; Mouser ve ark., 2017). KAK egzersizinin düzenli antrenmana eklenmesi hem güç hem de dayanıklılık antrenmanı almış sporcularda adaptasyonları geliştirmiştir (Luebbers, Fry, Kriley ve Butler, 2014; Scott, Loenneke, Slattery ve Dascombe, 2016; Wortman, Brown, Savage-Elliott, Finley ve Mulcahey, 2020). Bu derlemede, sporcuların fiziksel performansını geliştirme bağlamında KAK antrenmanındaki son gelişmeler vurgulanmaktadır. Derlemenin hedefleri:

1) Gerçekleştirilen KAK antrenmanının farklı özelliklerde ve antrene bireyler üzerindeki pozitif veya negatif etkilerini kanıtlarıyla incelemek;

2) KAK antrenmanının altında yatan olası mekanizmaları tartışmak;

3) Sporcularda KAK antrenmanının kullanımıyla ilgili bilgi boşluklarını ve gelecekteki araştırmaların yönlerini belirlemektir. KAK egzersizi ile ilgili güvenlik hususları bu derlemenin kapsamı dışında olup okuyucular bu konuyla ilgili son alanyazına yönlendirilmektedir (Cristina-Oliveira ve ark., 2020; Wernbom ve ark., 2020).

\section{Antrene Bireylerde KAK Egzersizinin Etkisi}

Bugüne kadar yapılan araştırmaların çoğu, antrenmansız katılımcılarda kas boyutunu ve gücünü artırmak için KAK direnç antrenmanının etkinliğini değerlendirmiştir (Gülfirat ve Bişgin, 2021). Son yapılan çalışmalar, KAK direnç egzersizinin antrenmanı etkilediğini ve bunun belirli popülasyonlardaki adaptasyonları olumlu yönde etkilediği vurgulanmaktadır. Kullanımında en etkili çıkarımın ise ulusal düzeyde mücadele eden powerlifterlarda gözlemlendiği ileri sürülmektedir (Bjørnsen ve ark., 2018). Yakın zamanda yapılan ve yaklaşık 1,5 ay süren güç çalışmasına düşük yüklerde sürekli KAK (\% 30 1-maksimum tekrar; 1-MT) ve konvansiyonel daha yüksek yüklerde (\% 60-85 1-maksimum tekrar; 1-MT) ön çömelmelerden oluşan, iki adet 1 haftalık blok program eklenmiştir. Katılımcıların mevcut gelişmiş antrenman seviyelerine rağmen, yalnızca on KAK seansının eklenmesi ile kuadriseps 
Yılmaz, D.A., ve Dege, G. (2021). Sporcularda Kan Akımı Kısıtlamalı Antrenman ve Fizyolojik Mekanizması. Gaziantep Üniversitesi Spor Bilimleri Dergisi, 6(3), 245-265.

kesit alanı (KKA) \% 3-8, bireysel kas lifi KKA'sı (\%12), myonüklei sayısı (\%18) ve Tip 1 kas lifleri için kapiler kas lif bağlantıları (\%12) artış göstermiştir. Diğer taraftan konvansiyonel antrenman yapan grupta, bu değişkenlerde genel bir değişiklik meydana gelmemiştir. Antrenman sonrası kuvvet değişiklikleri değerlendirmesinde, diz ekstansör pik izokinetik tork ve 1-MT ön çömelmede gruplar arasında istatistiksel bir fark bulunamamıştır. Çalışmada tepe tork veya 1-MT'deki değişiklikler için pozitif korelasyonlar $(r=0.63-0.79)$ bulunmasına rağmen, yalnızca KAK antrenmanını takiben kas boyutu indekslerinde değişiklikler gözlenmiştir.

Yapılan çalışmalar, kontrol antrenman gruplarına kıyasla, KAK antrenmanının eklenmesinin yarı profesyonel sporcularda gücü ve kas adaptasyonlarını artırdığını göstermektedir (Scott ve ark., 2016), örneğin; atlama gücü / yüksekliği ( \% 2-5), yön değişimi hızı ( \% 9), 5 m ve 10 m sürat koşusu süreleri ( \% 3-16), tekrar hızı ( \% $0,6)$ veya mekik koşusunu ( \% 5-20) olumlu yönde etkilediğini bildirilmektedir (Amani-Shalamzari ve ark., 2019; Amani-Shalamzari ve ark., 2020; Cook, Kilduff ve Beaven, 2014; Manimmanakorn, Hamlin, Ross, Taylor ve Manimmanakorn, 2013)

Ancak bu bulgular evrensel değildir. KAK antrenmanı almayan kontrol grubuyla karşılaştıııldığında, KAK-direnç antrenmanı veya KAK ile spora özgü antrenman alan futbolcularda (yarı profesyonel veya gençlik seviyeleri sporcularında) kas boyutu (Lignell, Fransson, Krustrup ve Mohr, 2018), tek atlama ve sprint performansları (Lignell ve ark., 2018; SA, Kianigul, Haghighi, Nooghabi ve Scott, 2020) gelişim göstermediği çalışmalar mevcuttur. Yukarıdaki tutarsızlıklar, KAK 'tan bağımsız olarak direnç egzersizinden hemen sonra yapılan dayanıklılık antrenmanlarından kaynaklanıyor olup (Scott, Peiffer ve Goods, 2017) bu da genel antrenman uyarlamalarını köreltmiş olabilir (Coffey ve Hawley, 2017). KAK 'la veya KAK olmadan gerçekleştirilen piliyometrik antrenman (SA ve ark., 2020), 40m sürat koşusu ve dikey sıçrama performanslarında neden benzer gelişmelerin gözlemlendiğini açıklayabilir.

Özetle, tamamlayıcı KAK antrenmanı; gücü, takım sporcularının bazı fiziksel özelliklerini ve spora özgü görev performanslarını artırabilir. KAK geleneksel antrenman yöntemlerine kıyasla iyi bir alternatif olarak değerlendirilebilir.

\section{KAK Egzersizinin Dayanıklılık Antrenmanı Almış Sporculara Etkisi}

Kısa süreli, yoğunlaştırımış, aralıklı antrenmanın atletlerde fizyolojik adaptasyonları ve performansı iyileştirebileceği ortaya konmuştur (Laursen, 2010). 
Yılmaz, D.A., ve Dege, G. (2021). Sporcularda Kan Akımı Kısıtlamalı Antrenman ve Fizyolojik Mekanizması. Gaziantep Üniversitesi Spor Bilimleri Dergisi, 6(3), 245-265.

KAK egzersizi tipik olarak direnç antrenmanı ile ilişkilendirilmiş olup ortaya çıkan kanıtlar KAK'ın atletlerde aralıklı antrenmanla fizyolojik yanıtı iyileştirebileceğini desteklemektedir.

Antrenmanlı bisikletçilerde ( $\overline{\mathrm{x}} \mathrm{VO} 2 \max >60 \mathrm{~mL}$. min-1.kg-1), dinlenme dönemlerinde KAK ile 4 haftalık tamamlayıcı sürat koşusu-interval antrenmanı (SKIA) VO2 maksimumu daha yüksek bir maksimum aerobik güç çıkışına ( \% 3-4) doğru bir eğilim ile \% 5-6 oranında artırmıştır (Mitchell, Martin, Turner, Taylor ve Ferguson, 2019; Taylor, Ingham ve Ferguson, 2016). KAK olmadan SKIA gerçekleştiren kontrol gruplarında ise hiçbir değişiklik meydana gelmemiştir. Bu çalışmalarda KAK, geleneksel uygulamanın aksine (yani egzersiz sırasında) her iyileşme döneminin ilk iki dakikasında uygulandığı takdirde dâhi bireylerde VO2 max gelişmelerinin mevcut olacağı görülmüştür. Ancak VO2 max 'taki yükselişin etkisi, sporcuların uzun yarış performanslarında etkili olmamıştır (Taylor ve ark., 2016). Kritik güç, KAK'sız SKIA'ya kıyasla benzer şekilde artış ( $\%$ 3) göstermiştir (Mitchell ve ark., 2019).Bu çalışmalara ek olarak, aerobik güç çıkışının büyük kısmını ortaya çıkarmak için tasarlanmış daha kısa ve yüksek yoğunluklu bir performans testi, performans avantajının tespiti açısından daha belirleyici olacaktır.

Tamamlayıcı KAK antrenmanı, düşük yoğunluklu aralıklarda yapıldığında da

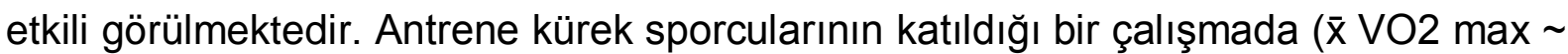
63 ml. min-1.kg-1), KAK ile haftada üç kez düşük hacimli (2x10 dakika), düşük yoğunluklu (ilk laktat eşiğinin altında) kürek çekme, 5 haftalık düzenli antrenmana eklenmiş ve KAK olmadan antrenmana devam eden bir kontrol grubuyla karşılaştırılmıştır (Morgan, Daniels ve Subramaney, 2019). Sonuç olarak KAK grubu kürekçilerde VO2 max ve maksimal aerobik güç çıkışında oldukça fazla ilerleme kaydedilmiştir. Ancak araştırmada rekabet-performans ilişkisi tespit edilmediği için aerobik parametrelerin değerlendirilmesi bir yana, sporcuların gerçek performansı hâlâ soru işareti oluşturmaktadır. Çalışmalar, kısa süreli (4-5 hafta) supramaksimal veya düşük yoğunluklu KAK antrenmanının; dayanıklılık antrenmanı almış sporcuların aerobik gücünü artırabileceğini göstermektedir. Ancak bu faydaların rekabet performansına çevrilmesi için daha fazla değerlendirmeye intiyaç duyulmaktadır. 


\section{KAK Egzersizi Sonrası Fizyolojik Adaptasyonlar}

Yukarıdaki bahsi geçen bulgular, çeşitli egzersiz modaliteleri kullanan tamamlayıcı KAK antrenmanının, geleneksel egzersiz antrenmanına kıyasla farklı branş sporcularında egzersiz yanıtını iyileştirebileceğini göstermektedir. Ancak, KAK'ın bunu nasıl yaptığı önemlidir. Elde edilen bulgular istenen fiziksel özelliklerin geliştirilmesi amacıyla hazırlanacak antrenman programlarına iyi kılavuz olacaktır.

Söz konusu bölüm, kas iskelet sistemi ve kardiyovasküler fizyolojik adaptasyonlara, KAK'ın fiziksel performans ile olan ilişkisine ve altta yatan olası mekanizmalara değinecektir. Fizyolojik mekanizmalarda gerçekleşen her yapısal ve fonksiyonel değişikliğin tüm sporcu ve antrene bireylerde geçerli olamayabileceği göz önüne alınmalıdır.

\section{Kas Kuvveti ve Fizyolojik Adaptasyonlar}

Kuvvet ve kondisyon programlarının büyük bir kısmı, bireylerin güç üretim kapasitelerini artırmayı hedeflemektedir ancak güç gelişimi hakkındaki fikirleri değerlendirmek için temel olarak kesin bir güç tanımına sahip olmamız gerekmektedir. 'Güç' terimiyle tam olarak neyi kastediyoruz? Hepimiz hemfikir olabiliriz güç, insan performansının bir ölçüsüdür. Ancak güç tanımı farklı konseptlerde farklılaşmaya gitmektedir. Statik güç, dinamik güç, izometrik güç, izokinetik güç, izotonik güç, patlayıcı güç ve kas gücü gibi farklı alt dallara ayrılmıştır (Enoka, 1988).

Genel tanımıyla herhangi bir cisme karşı maksimal kuvvet üretme kabiliyetinin yükseltilmesi olarak tanımlanan kas gücü, maksimal olmayan hareketlere, sürat koşusu ve sıçrama gibi piliyometrik hareketlere uyum sağlayarak performansı artırmaktadır (Suchomel, Nimphius ve Stone, 2016). Düşük yük KAK-direnç antrenmanının ise, antrenmansız ve rekreasyonel kişilerde yüksek yük direnç antrenmanına benzer etki gösterdiği ve kas gücünü geliştirdiği belirtilmiştir (Grønfeldt, Lindberg Nielsen, Mieritz, Lund ve Aagaard, 2020). Kuvvette üstün iyileştirmeler olduğunu dile getiren başka çalışmalar da mevcuttur (Lixandrao ve ark., 2018).

Kas büyüklüğü ve gücü arasındaki doğrudan ilişki, bu iki faktör arasında bir neden-sonuç ilişkisi belirtmenin zorluğu sebebiyle tartışmalara açıktır (Nuzzo, Finn ve Herbert, 2019). Mikro (hücre altı hipertrofi) ve makro (fizyolojik KKA) seviyelerdeki kas terkibi ve yapısının, fonksiyonel çıktıyı ve kuvvet üretme kabiliyetini etkileyebileceği düşünülebilir (Narici, Franchi ve Maganaris, 2016). 
Yılmaz, D.A., ve Dege, G. (2021). Sporcularda Kan Akımı Kısıtlamalı Antrenman ve Fizyolojik Mekanizması. Gaziantep Üniversitesi Spor Bilimleri Dergisi, 6(3), 245-265.

Miyofibriler protein sentezi, rekreasyonel olarak aktif ( $\leq 1$ gün / hafta direnç egzersizi) bireylerde geleneksel kontrol grubuna kıyasla düşük yüklü KAK direnç egzersiz seansını takiben ( \% 10) artı̧̧ göstermiştir (Nyakayiru ve ark., 2019). Antrenmanla birlikte, günlük miyofibriler protein sentezi, egzersiz yapmamış bireylerde dahi; düşük yüklü KAK ve yüksek yük direnci antrenmanına benzer şekilde artı̧̧ göstermiştir (Sieljacks ve ark., 2019). Bu da birkaç kasılma biriminde olası bir artışı düşündürmektedir. Kontrol grubuyla kıyaslandığında, kısa süreli ( $\leq 3$ hafta) hafif KAK direnç antrenmanının kas hacmini ( \%7-10) artırdığı tespit edilmiştir (Abe, Kearns ve Sato, 2006).

Bu modalitelerin kas boyutunu artırmak için optimal olup olmadığı bir tartışma konusu olmasına rağmen, düşük yoğunluklu bir yürüyüş veya bisiklet antremanı sırasında (Abe ve ark., 2010; Abe ve ark., 2006) KAK uygulandığında kas hacminin arttığı bilinmektedir ( \%4-8). KAK'la veya KAK olmadan istemli yorgunluğa düşük yük egzersizi uygulandığında egzersiz yapmamış ve direnç antrenmanı almış kişilerde kas boyutu benzer şekilde ( \% 5-12) artış göstermiştir (Pignanelli ve ark., 2020). İyi antrenmanlı güç kaldırıcılarda geleneksel yüksek yük antrenmanına kıyasla KAK direnç antrenmanının eklenmesiyle kas boyutunun daha fazla artması dikkat çekicidir (Bjørnsen ve ark., 2018). Ancak bu artış, 1.5 ay boyunca düşük yük KAK ve yüksek yük direnç antrenmanını belirli bir döngüde gerçekleştiren rekreasyonel bireylerde geçerli değildir (Hansen ve ark., 2020).

KAK egzersizinin, geleneksel antrenman yöntemlerine alışkın olan antrene ve aktif bireylerde güçlü bir uyarıcı olarak etki edebileceği öngörülmektedir. Araştırmacılar tarafından alanyazı incelendiğinde; hiçbir çalışmada, antrenman durumunun KAK egzersizinin hipertrofik yanıtı etkileyip etkilemediği araştırımadığı saptanmıştır. Bununla birlikte, bugüne kadarki kanıtlara dayanarak, güçlü bir hipertrofik antrenman yanıtı ortaya çıkarmak için KAK antrenmanında dengeli dış yoğunluklarda / yüklerde daha fazla çalışma yapılması gerekir ki bu, potansiyel kas kütlesi kazanımını en üst düzeye çıkarmak için yapılacak yönlendirmeler açısından önemlidir.

Kas gücünün artırılması amacıyla vücutta bazı sinirsel adaptasyonlar oluşturulmaktadır. Bununla birlikte, KAK antrenmanının kas boyutunu artırmadaki açık etkilerinin aksine, şu anda nöral adaptasyonlarla ilgili kesin sonuçlara varılamamaktadır. Bu kısmen, KAK antrenmanına nöral adaptasyonları doğrudan araştıran çalışmaların az olmasından ve bu çalışmaların genelde düşük yük KAK- 
Yılmaz, D.A., ve Dege, G. (2021). Sporcularda Kan Akımı Kısıtlamalı Antrenman ve Fizyolojik Mekanizması. Gaziantep Üniversitesi Spor Bilimleri Dergisi, 6(3), 245-265.

direnç antrenmanı ile artan kas uyarılabilirliğini ortaya çıkarmak için yüzey EMG (Elektromiyografi) kullanılmasından kaynaklanmaktadır (Centner ve Lauber, 2020). Nöromüsküler adaptasyonları antrenmana yorumlarken sadece yüzey EMG değişkenlerindeki değişiklikler yeterli olmayabilir çünkü yüzey EMG, kuvvet üretimini de etkileyebilecek spesifik lokomotor/nöral aktivasyon kalıplarının değişip değişmediğini açıklığa kavuşturamamaktadır (Vigotsky, Halperin, Lehman, Trajano ve Vieira, 2018). Bu nedenle; KAK antrenmanını takiben merkezi ve periferik sinir sistemleri boyunca, adaptasyonları netleştirmek için gelecekte ek çalışmalara intiyaç vardır.

\section{Kas Redoksu ve İyonik Tamponlama}

Kas yorgunluğu çok faktörlüdür ve yapılan işe bağlıdır. Bununla birlikte, tipik olarak kısa süreli ( $\leq 10$ dakika) bir dizi fiziksel çabadan kaynaklanan yorgunluk, miyoselüler redoks stresi (Christiansen, 2019) ve iyonik düzensizlikler (Hostrup ve Bangsbo, 2017) ile ilişkilendirilmiştir. Egzersiz anında, redoks ve iyonik homeostazın sağlıklı bir şekilde sürdürülebilmesi, kişinin performansı açısından büyük önem taşımaktadır. Kas fonksiyonunun iyon transferi için acil talebi, antioksidan aktivite veya her ikisinin birden antrenmanla geliştiği ifade edilmektedir (Christiansen, 2019; Hostrup ve Bangsbo, 2017). Bu araştırma alanı henüz alanyazında yeni araştıılan konulardan biri olsa da, aerobik antrenmanlı bireylerde aralıklı çalışan döngüsel KAK'ın $\left(\bar{x} \mathrm{VO}_{2}\right.$ max $\sim 57 \mathrm{ml}$. $\left.\mathrm{min}^{-1} \cdot \mathrm{kg}^{-1}\right)$ iyon taşınımıyla ilişkili belirteçleri artırdığı belirlenmiştir (Christiansen, Murphy, Bangsbo, Stathis ve Bishop, 2018).

Döngüsel KAK protokolü kullanılarak, rekreasyonel olarak aktif bireylerde 6 haftalık aralıkı bisiklet antrenmanı yapılan bir çalışmada $\left(\overline{\mathrm{x}} \mathrm{VO}_{2} \max \sim 50 \mathrm{ml}\right.$. $\mathrm{min}^{-1}$. $\mathrm{kg}^{-1}$ ) diz ekstansörlerinin çalışma kapasitesi, geleneksel kontrol gruba kıyasla büyük miktarda artış göstermiştir (\%23'e karşı \%11) (Christiansen, 2019; Christiansen, Eibye, Hostrup ve Bangsbo, 2020; Christiansen ve ark., 2019). Performanstaki gelişmeler, kastaki sodyum-potasyum pompasının alt biriminde bulunan (tip-II a1 ve tip-ßl içeriği) fosfolemman içerikle ve kas tipine özgü farklılaşmalarla ifade edilebilmektedir.

Yüksek yoğunluklu egzersiz performansının kritik belirleyicisi olan potasyum iyon düzenlenmesi (Christiansen, 2019) ve iyileştirmeye katkıda bulunabilecek diğer tüm uyarlamalar KAK antrenmanından sonra sporcuların tekrarlanan sürat koşusu ve standart koşu performanslarını iyileştirmeye katkıda bulunmuş olabilir (Amani- 
Yılmaz, D.A., ve Dege, G. (2021). Sporcularda Kan Akımı Kısıtlamalı Antrenman ve Fizyolojik Mekanizması. Gaziantep Üniversitesi Spor Bilimleri Dergisi, 6(3), 245-265.

Shalamzari ve ark., 2019; Amani-Shalamzari ve ark., 2020; Cook ve ark., 2014; Manimmanakorn ve ark., 2013; SA ve ark., 2020). Bu bulguları doğrulamak ve farklı KAK egzersiz modlarında benzer adaptasyonların meydana gelip gelmediğini açıklığa kavuşturmak için gelecekte ek çalışmalara intiyaç vardır.

\section{Kas Oksidatif Kapasitesi}

İskelet kasının oksidatif kapasitesinin yüksek olması; kan oksijen ekstraksiyonunu sağlamak, yüksek aerobik çalışma çıktılarını korumak ve tekrarlanan yüksek yoğunluklu aktiviteleri gerçekleştirmede büyük öneme sahiptir. Önceleri kas oksidatif kapasitesindeki gelişmelerin mitokondriyal içerik miktarına bağlı olduğu düşünülüyordu ancak son bulgular, antrenmanın içerikteki değişikliklerden bağımsız olarak mitokondriyal işlevi değiştirebileceğini göstermektedir (Larsen ve ark., 2020).

Akut egzersiz sırasında gerçekleşen miyoselüler stres ve egzersizin ardından gerçekleşen transkripsiyonel ve translasyonel olaylar, mitokondriyal mekanizmanın yapıtaşlarını oluşturur (Egan, O'connor, Zierath ve O'gorman, 2013). Egzersiz, KAK ile birleştirildiğinde azalmış kan kaynaklı substrat mevcudiyeti (örn. oksijen ve hücre dışı yakıt kaynakları), ATP üretimi için yerel substratlara (örn. glikojen) olan bağımlılığı artırır. Metabolizmadaki bu değişiklikler, yukarıda belirtilen stres ve sinyal olaylarını derinleştirebilir ve sonuç olarak mitokondriyal adaptasyonları güçlendirebilir. Mitokondriyal biyogenez ile ilişkili erken dönem hücresel yanıtlar ve / veya gen ekspresyonu; kontrol grubuna kıyasla, düşük yük KAK direnci egzersizi (Ferguson ve ark., 2018) ve orta yoğunlukta sürekli (Preobrazenski ve ark., 2020; Taylor ve ark., 2007) veya aralıklı KAK dayanıklılık egzersizi sonrası artış göstermektedir (Christiansen ve ark., 2018).

Bu bilgilerin aksine alan yazında tutarsızlıklar da görülebilmektedir. Maksimal bisiklet antrenmanı (Taylor ve ark., 2016) sonrası veya 15 dakikalık düşük yoğunluklu bisiklet antrenmanı (Conceicao ve ark., 2016) sırasında uygulanan KAK, p38-MAPK ve AMPK $\alpha$ fosforilasyonunu veya PGC-1 $\alpha$ mRNA ekspresyonunu değiştirmemiştir. Aksi bir çalışma, kontrollerle karşılaştırıldığında, p38-MAPK fosforilasyonu ve PGC$1 \alpha$ protein bolluğunun (Barjaste, Mirzaei, Rahmani-Nia, Haghniyaz ve Brocherie, 2021) düşük yoğunluklu KAK-koşu bandı yürüyüşünden 3 saat sonra arttığını dile getirmiştir. Grup içi sayıların düşük olması, incelenen sinyal proteinlerinin yetersizliği ve çalışmada gen ekspresyon analizlerinin bulunmaması sebebiyle bu çalışmaların 
Yılmaz, D.A., ve Dege, G. (2021). Sporcularda Kan Akımı Kısıtlamalı Antrenman ve Fizyolojik Mekanizması. Gaziantep Üniversitesi Spor Bilimleri Dergisi, 6(3), 245-265.

değerlendirilmesinde daha titiz olunması gerekmektedir (Barjaste ve ark., 2021; Ozaki ve ark., 2014).

Groennebaek ve diğ. yaptığı bir çalışmada; 1,5 aylık süre boyunca uygulanan düşük yük KAK direnç antrenmanı, yüksek yük direnç antrenmanına benzer şekilde kas içi mitokondriyal protein sentezini ve solunum kapasitelerini artırmıştır (Groennebaek ve ark., 2018). İsteğe bağlı yorgunluğa düşük yük direnci antrenmanı yapıldığında, KAK'ın eklenmesi mitokondriyal solunum kapasitesini daha fazla arttırmamıştır. Ayrıca, mitokondriyal içerik için yaygın olarak kullanılan belirteçler (COXIV protein bolluğu ve sitrat sentaz aktivitesi) bu çalışmalarda değişmemiştir (Groennebaek ve ark., 2018; Pignanelli ve ark., 2020). KAK ile orta yoğunlukta yapılan bisiklet antrenmanının (45 dakika / seans / 4 hafta), sitrat sentaz aktivitesini ( \% 20) oranında arttırdığı tespit edilmiştir (Esbjörnsson ve ark., 1993). KAK ile düşük yoğunluklu bisiklet antrenmanını (30 dakika / seans) takiben kas COXIV bolluğu başlangıca göre ( \% 20) artış göstermiştir (Miguel S Conceicao ve ark., 2019). KAK-interval antrenmanının kas oksidatif kapasitesi üzerindeki olumlu etkileri, kas difüzyonel $\mathrm{O}_{2}$ iletkenliğini (Christiansen ve ark., 2020) ve oksijen kinetiğini (Corvino, Oliveira, Denadai, Rossiter ve Caputo, 2019) iyileştiren döngüsel KAK ile 46 haftalık bisiklet-interval antrenmanıyla da gösterilmiştir. $\mathrm{VO}_{2}$ max'daki iyileşmelere rağmen; dinlenme aralıklarında, KAK ile 4 haftalık supramaksimal bisiklet antrenmanından sonra kas oksidatif kapasitesi (COXIV, COXII ve sitrat sentaz protein bolluğu) belirteçlerinde beklenen yüksek artış gerçekleşmemiştir (Mitchell ve ark., 2019).

Özetle, KAK antrenmanı ile daha büyük bir çalışma kapasitesi ve/veya $\mathrm{VO}_{2}$ max bulguları bulunmasına rağmen kas oksidatif kapasitesindeki artışlar, gerçekleştirilen KAK antrenmanının türüne bağlı görünmektedir. Çalışmaların bir kısmı mitokondriyal solunumda fonksiyonel parametrelerle ilgilenmiştir. Bu konuda yapılan çalışmalar, antrenmandan sonra mitokondriyal ağdaki yapısal ve fonksiyonel değişikliklere ait içeriği tahmin etmek için mitokondriyal proteinleri araştırmıştır (Lundby ve ark., 2018). KAK antrenmanı yapan sporcularda kas oksidatif kapasitesini artırma potansiyeli, farklı mekanizmalar yoluyla ortaya çıkıyor olabilir. Aralıklı KAK antrenmanı, mitokondriyal içeriğin belirteçlerindeki güçlü artışlardan bağımsız olarak iskelet kasının mitokondriyal işlevini iyileştirirken; sürekli, kararlı KAK antrenmanı mitokondriyal içeriği artırabilir. 
Yılmaz, D.A., ve Dege, G. (2021). Sporcularda Kan Akımı Kısıtlamalı Antrenman ve Fizyolojik Mekanizması. Gaziantep Üniversitesi Spor Bilimleri Dergisi, 6(3), 245-265.

KAK'ın kas oksidatif kapasitesi üzerindeki etkilerinin netleştirilmesi amacıyla gelecekte ek çalışmalara intiyaç vardır.

\section{Kardiyovasküler Adaptasyonlar}

Kardiyorespiratuar sistem birçok önemli görevi üstlenmektedir. Bu sistem; substratların taşınımı, yan ürünlerin uzaklaştırılması da dâhil olmak üzere insan bedeninde gerçekleşen bütün düzenleyici sistemlerde aktif rol oynamaktadır. Bu nedenle, sporcular; kas içi fizyolojilerini sürdürme veya iyileştirmenin yanı sıra, gelişmiş bir kalp-solunum sistemine de sahip olmalıdır. Kalpten mikro damar sistemine kadar geniş bir ağ yapısı oluşturan kardiyovasküler sistem, maksimum kardiyak çıktı (Qmax) ve a-̄̄O2 farkının ürünü tarafından belirlenen tüm vücut VO2 max'ını güçlü bir şekilde yönetmektedir.

Egzersiz durumundan (Skattebo, Calbet, Rud, Capelli ve Hallén, 2020) ve hastalık / sağlık durumundan (Poole, Behnke ve Musch, 2021) etkilenebilen VO2 max'ı sınırlandıran faktör (ler), sistemik oksijen dağıtımının (Qmax ve arteriyel oksijen içeriğinin ürünü; $\mathrm{CaO} 2$ ) oksijen ekstraksiyonu (a-v̄O2 farkı / CaO2) ile etkileşimine bağlıdır. Bu faktörler çok değişkenli olmasına ve birbirini dışlamamasına rağmen, son kanıtlar, aktif kaslara oksijen verilmesinin, dayanıklılık antrenmanı yapan bireylerde iskelet kasının iç mitokondriyal solunum kapasitesinin aksine VO2 max'ı sınırlayabileceğini göstermektedir (Gifford ve ark., 2016). Mitokondriyal solunum kapasitesi, antrenmansız bireylerde VO2max'ın sınırlanmasında rol oynayabilir.

Dayanıklılık antrenmanı yapan bireylere karşı antrenmansız bireylerde farklı VO2 max sınırlamalarının olması ilgi çekicidir. KAK antrenmanının egzersiz modu veya yoğunluğu ne olursa olsun hem antrenmansız (Abe ve ark., 2010; Conceicao ve ark., 2019; de Oliveira, Caputo, Corvino ve Denadai, 2016) hem de antrenmanlı bireylerde (Mitchell ve ark., 2019; Morgan ve ark., 2019; Taylor ve ark., 2016) VO2 max'ı geliştirdiği belirtilmiştir. Kondüit arter kan akımında ve kas kılcal yoğunluğunda artış gibi vasküler ağaç boyunca görülen lokal adaptasyonlar ve yüksek oksidatif kapasite gibi iskelet kası içinde oluşan gelişmeler KAK antrenmanını takiben VO2 max'ın artmasına katkıda bulunmaktadır (Christiansen ve ark., 2020; Esbjörnsson ve ark., 1993). Qmax ve VO2 max (Skattebo ve ark., 2020) arasında bulunan güçlü ortaklık değerlendirildiğinde, belirli kardiyovasküler adaptasyonlar, (örneğin dayanıklılık sporcularında) VO2 max'ta yükselmeleri desteklemiş olabilir (Mitchell ve ark., 2019; Morgan ve ark., 2019; Taylor ve ark., 2016). Dayanıklılık antrenmanı 
Yılmaz, D.A., ve Dege, G. (2021). Sporcularda Kan Akımı Kısıtlamalı Antrenman ve Fizyolojik Mekanizması. Gaziantep Üniversitesi Spor Bilimleri Dergisi, 6(3), 245-265.

almış sporcularda, SKIA + KAK (Mitchell ve ark., 2019) ile VO2 max'daki güçlü artışlara rağmen, kas kılcallığında veya mitokondriyal protein içeriğinde bir artış olmaması, merkezi kardiyovasküler iyileşmeler fikrini desteklemektedir. Bugüne kadar, KAK antrenmanını takiben kardiyak yapı ve fonksiyondaki değişiklikleri doğrudan araştıran bir çalışma yapılmamıştır. Teorikte, KAK egzersizi (Renzi, Tanaka ve Sugawara, 2010) ile kardiyak talebin artması, sol ventrikül boyutunda artış gibi kardiyak yapısal adaptasyonları hızlandırabilir, bu da atım hacmini ve dolayısıyla Qmax'ı yükseltebilir. Bu öneri cazip olsa da kalpteki yapısal değişiklikler için aylar süren antrenmanlar gerekmektedir (Hellsten ve Nyberg, 2011).

Yakın zamanda yapılan bir çalışmada kısa süreli antrenmanda plazma hacmi ve hemoglobin kütlesi gibi hematolojik değişkenlerin, atım hacmini ve sistemik oksijen dağııımını yükseltmek için artabileceği söylenmiştir (Hellsten ve Nyberg, 2011). Bu olasılıkların KAK antrenmanı içinde geçerli olup olmayacağı araştırımalıdır.

Geleneksel egzersizle kıyaslandığında, KAK egzersizi eşsiz bir kan akım modeli sunmaktadır. KAK egzersizi sırasında kas oksijen mevcudiyeti azalır, bu da yerel vazodilatör maddelerin vaskülatürden ve kasılan kaslardan salınmasını uyarır. Gerçekleşen kan akımındaki artış, vasküler kayma stresini belirli bir süre artırmaktadır (Christiansen ve ark., 2019). Hem egzersiz sırasında kas oksijen arzının azalması hem de egzersiz sonrası vasküler kayma stresinin artması, KAK antrenmanının, periferik vasküler damarlanma boyunca iskelet kası kan perfüzyonunda adaptasyonları teşvik edebileceğini desteklemektedir (Christiansen ve ark., 2019; Esbjörnsson ve ark., 1993).

KAK dayanıklılık ve direnç egzersizi, anjiyogenez organizasyonunda bulunan mRNA'yı hızıı biçimde yükselterek pozitif destek sağlamaktadır (Ferguson ve ark., 2018; Gustafsson, Puntschart, Kaijser, Jansson ve Sundberg, 1999) ayrıca birkaç hafta boyunca yapıldığında, kontrol grubuna kıyasla kılcal ağ yapısını ( \%20-40) genişlettiği bildirilmektedir (Esbjörnsson ve ark., 1993; Nielsen ve ark., 2020). Bununla birlikte, istemli yorgunluğa karşı direnç antrenmanı uygulandığında, mikrovasküler genişleme KAK ile ( \%14-18) oranında artış göstermiştir (Pignanelli ve ark., 2020). Bu bulgular, KAK'ın dayanıklıık veya direnç egzersizine eklenmesinin, kısa süreli anjiyojenik yanıtı artırdığını göstermektedir. Dahası KAK direnç antrenmanı; direnci, kondüit vasküler işlevi ve yapıyı olumlu yönde etkilemektedir (Hunt, Galea, Tufft, Bunce ve Ferguson, 2013; Hunt, Walton ve Ferguson, 2012). Bu durumun aksine KAK antrenmanıyla vasküler işlevde bozulmaları belirten çalışmalar 
Yılmaz, D.A., ve Dege, G. (2021). Sporcularda Kan Akımı Kısıtlamalı Antrenman ve Fizyolojik Mekanizması. Gaziantep Üniversitesi Spor Bilimleri Dergisi, 6(3), 245-265.

da mevcuttur (Credeur, Hollis ve Welsch, 2010). Bu tutarsızlık, egzersiz yoğunluklarının ve KAK süresinin farkından kaynaklanıyor olabilir.

İskemik ön koşullandırma (Jones ve ark., 2015) ve egzersiz antrenmanı (Tinken ve ark., 2010) ile vasküler yapı ve / veya işlevin nasıl iyileştirildiğini görmek için, birleşik uygulama ile (döngüsel KAK egzersizi) aditif veya sinerjistik bir vasküler etki üretebilir. Ancak şu anda sınırlı deneysel kanıtlar mevcuttur. 6 haftalık aralıklı KAK bisiklet antrenmanına yanıt olarak, yüksek yoğunlukta, diz ekstansör oksijen dağıtımının (artan pik güç çıkışının \%90'ı) başlangıç seviyesinden \%13 arttığı görülürken, serbest akım durumu antrenman ile iyileşmemiştir (Christiansen ve ark., 2020). Bu çalışma KAK -interval antrenmanı ile perifer mekanizmalara doğru genişletilmiş bir oksijen taşıma kapasitesini desteklemektedir. Aynı mutlak iş yükü için geliştirilmiş oksijen dağıtımı, egzersiz yapan kaslarda metabolik taleplere sağlanan oksijen dağıtımını kolaylaştırabileceğinden ve sporcuların daha yüksek performans göstermesine izin vererek yorgunluğu geciktirebileceğinden, spor performansı için umut vericidir.

\section{Tartışma ve Sonuç}

Düzenlenecek ve yapılandırılacak olan antrenman programlarına KAK egzersizi eklenmesinin, bireyin rekabet içerisinde bulunduğu spor dalında göstereceği fizyolojik performansı geliştirebileceği gösterilmiştir. Araştırmalar, KAK eklenmesinin güç ve dayanıklılık performanslarında mekanik iyileştirmeyi nasıl sağlayabileceğini ortaya çıkarmaya başlamıştır. Laboratuvarda elde edilen bulguları gerçek uygulamalara dönüştürmek için daha fazla çalışma yapılması gerekmektedir. KAK çeşitli egzersiz modları ve yoğunlukları ile uygulandığında geniş bir adaptasyon yelpazesi oluşturmaktadır (Şekil 1).

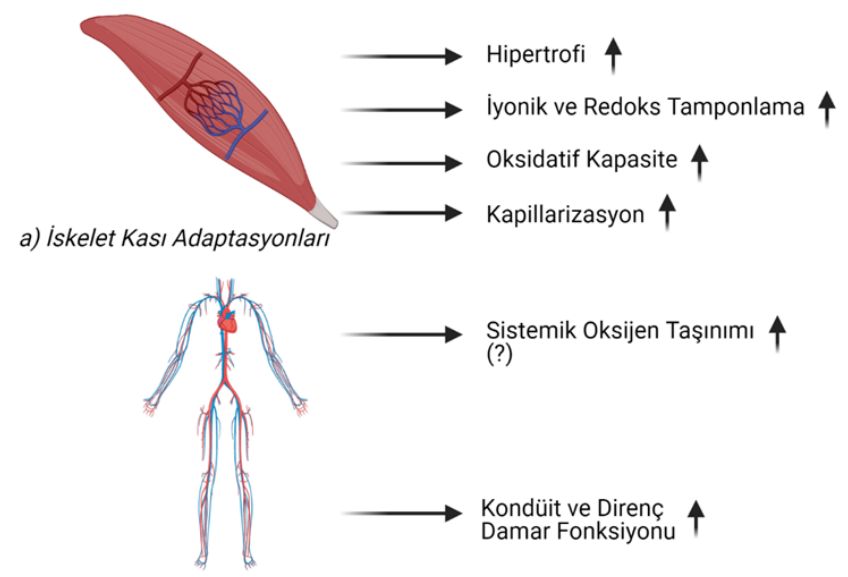


Şekil 1. Kontrol grubuna kıyasla kan akımı kısıtlama antrenmanı ile geliştirilmiş olası iskelet kası (a) ve kardiyovasküler adaptasyonları (b) gösteren şematik bir diyagram. Sistemik oksijen dağıtımı dışında her bir ek, mevcut alanyazına dayanılarak türetilmiştir.

KAK alanyazını, klasik formatta tanımlanmış "dayanıklılık" ve "direnç" antrenman uyarlamalarının birbirinden ayrı değil, bir süreklilik boyunca aynı anda nasıl gerçekleştiğinin iyi birer örneğidir. Bu durumun aksine farklı egzersiz modlarıyla KAK egzersizlerinin birlikteliği, KAK antrenmanı sonrası gerçekleştiği görülen fizyolojik değişiklilerin tespitinde yanıltıcı olabilir. Temel egzersiz değişkenlerine (süre, sıklık ve yoğunluk) dikkat edilerek, iskelet kası, nöral ve kardiyovasküler sistemlerin KAK tarafından yönlendirilen akut fizyolojik değişikliklere nasıl uyum sağlayacağına dair daha fazla bilgiye intiyaç vardır. Elit bir sporcu ile KAK antremanının gerçek zamanlı uygulanabilirliği, KAK tarafından uyarılan antrenman uyarlamalarının periyodik antrenman programına en iyi şekilde nasıl uyduğunu da gösterecektir.

KAK egzersizi gerçekleştirmenin, antrene bireylerde kısa süreli vücut adaptasyonları sağladığı kanıtlanmış olsa da, en etkili uygulama şekli yapılacak yeni çalışmalarla belirlenecektir (ŞEKIL 2).

A)

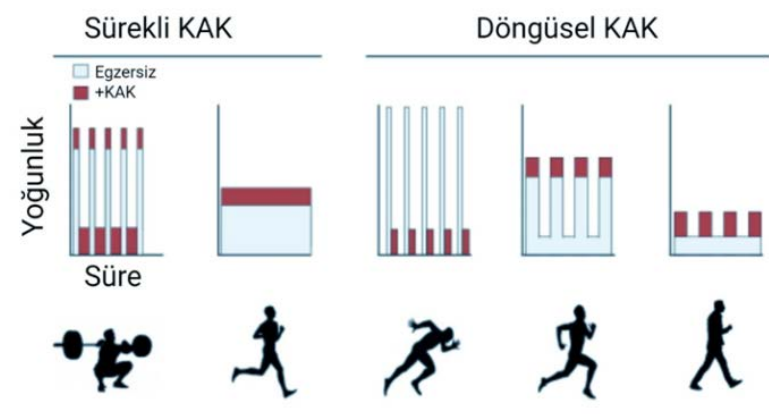

B)

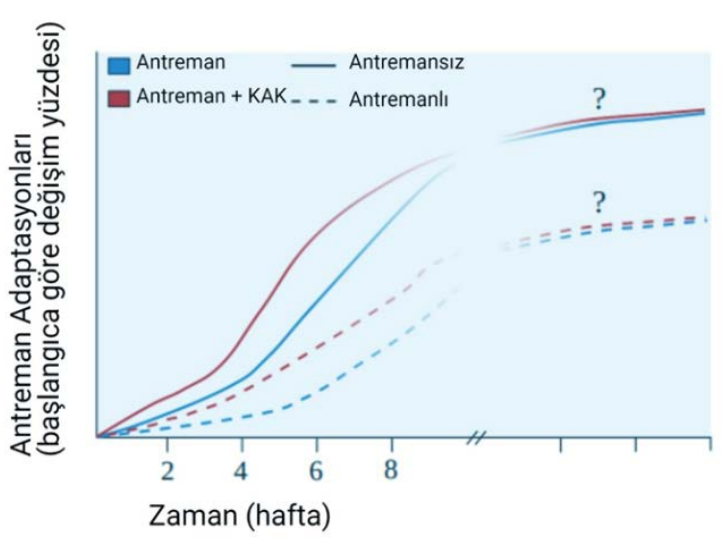


Şekil 2. (A) Farklı egzersiz yoğunluğu, süresi ve sıklığı ile kan akımı kısıtlama uygulamalarının özeti. Egzersiz modları esnektir ve farklılaştırılabilir. Antrenmansız (düz çizgiler) ve antrenmanlı (kesikli çizgiler) durumlarda (mavi) veya (kırmızı) KAK ile antrenman uyarlamalarının varsayımsal bir gösterimi. KAK eklenmesinin, her iki senaryoda da antrenmanın başlangıcında uyarlamaları hızlandırabileceği ancak değişimin büyüklüğü ve zaman çizelgesinin farklı olabileceği unutulmamalıdır.

Sporcular için KAK içeren antrenmanının anlaşılmasındaki bir başka mevcut sınırlama ise, mekanizmaya ait bilgilerin çoğunun rekreasyonel olarak aktif veya antrenmansız bireylerden derlenmiş olmasıdır. Antrenman durumu egzersize tepkiyi etkilediğinden, sporcunun KAK egzersizine verdiği tepkinin karakterize edilmesi gereklidir. Bununla birlikte, KAK'ın fizyolojik adaptasyonları nasıl etkilediğini anlamadaki son gelişmeler, KAK egzersizinin iyi hedeflenmiş uyarlamalarını sağlayarak sporcuların fiziksel performanslarının optimizasyonunda kolaylık sağlayacaktır.

\section{Kaynaklar}

Abe, T., Fujita, S., Nakajima, T., Sakamaki, M., Ozaki, H., Ogasawara, R., . . . Yasuda, T. (2010). Effects of low-intensity cycle training with restricted leg blood flow on thigh muscle volume and VO2max in young men. Journal of sports science ve medicine, 9(3), 452.

Abe, T., Kearns, C. F. ve Sato, Y. (2006). Muscle size and strength are increased following walk training with restricted venous blood flow from the leg muscle, Kaatsu-walk training. Journal of applied physiology, 100(5), 1460-1466.

Amani-Shalamzari, S., Farhani, F., Rajabi, H., Abbasi, A., Sarikhani, A., Paton, C., . . . Nikolaidis, P. T. (2019). Blood flow restriction during futsal training increases muscle activation and strength. Frontiers in physiology, 10, 614.

Amani-Shalamzari, S., Sarikhani, A., Paton, C., Rajabi, H., Bayati, M., Nikolaidis, P. T. ve Knechtle, B. (2020). Occlusion Training During Specific Futsal Training Improves Aspects of Physiological and Physical Performance. Journal of sports science ve medicine, 19(2), 374.

Barjaste, A., Mirzaei, B., Rahmani-Nia, F., Haghniyaz, R. ve Brocherie, F. (2021). Concomitant aerobic-and hypertrophy-related skeletal muscle cell signaling following blood flow-restricted walking. Science ve Sports, 36(2), e51-e58. 
Bjørnsen, T., Wernbom, M., Kirketeig, A., Paulsen, G., Samnøy, L. E., Bækken, L. V., . . . Raastad, T. (2018). Type 1 Muscle Fiber Hypertrophy after Blood Flowrestricted Training in Powerlifter.

Centner, C. ve Lauber, B. (2020). A Systematic Review and Meta-Analysis on Neural Adaptations Following Blood Flow Restriction Training: What We Know and What We Don't Know. Frontiers in physiology, 11, 887.

Christiansen, D. (2019). Molecular stressors underlying exercise training-induced improvements in $\mathrm{K}+$ regulation during exercise and $\mathrm{Na}+, \mathrm{K}+-\mathrm{ATPase}$ adaptation in human skeletal muscle. Acta physiologica, 225(3), e13196.

Christiansen, D., Eibye, K., Hostrup, M. ve Bangsbo, J. (2020). Training with blood flow restriction increases femoral artery diameter and thigh oxygen delivery during knee-extensor exercise in recreationally trained men. The Journal of physiology, 598(12), 2337-2353.

Christiansen, D., Eibye, K. H., Rasmussen, V., Voldbye, H. M., Thomassen, M., Nyberg, M., . . . Bishop, D. J. (2019). Cycling with blood flow restriction improves performance and muscle $\mathrm{K}+$ regulation and alters the effect of antioxidant infusion in humans. The Journal of physiology, 597(9), 2421-2444.

Christiansen, D., Murphy, R. M., Bangsbo, J., Stathis, C. G. ve Bishop, D. J. (2018). Increased FXYD1 and PGC-1 $1 \alpha$ mRNA after blood flow-restricted running is related to fibre type-specific AMPK signalling and oxidative stress in human muscle. Acta physiologica, 223(2), e13045.

Coffey, V. G. ve Hawley, J. A. (2017). Concurrent exercise training: do opposites distract? The Journal of physiology, 595(9), 2883-2896.

Conceicao, M. S., Junior, E. M., Telles, G. D., Libardi, C. A., Castro, A., Andrade, A. L., . . . Júnior, J. M. C. (2019). Augmented anabolic responses after 8-wk cycling with blood flow restriction. Medicine and science in sports and exercise, 51(1), 84-93.

Conceicao, M. S., Traina Chacon-Mikahil, M. P., Telles, G. D., Libardi, C. A., Mendes Junior, E. M., Vechin, F. C., . . . Cavaglieri, C. R. (2016). Attenuated PGC-1 alpha Isoforms following Endurance Exercise with Blood Flow Restriction. Medicine and science in sports and exercise, 48(9), 1699-1707.

Cook, C. J., Kilduff, L. P. ve Beaven, C. M. (2014). Improving strength and power in trained athletes with 3 weeks of occlusion training. International journal of sports physiology and performance, 9(1), 166-172. 
Corvino, R. B., Oliveira, M. F., Denadai, B. S., Rossiter, H. B. ve Caputo, F. (2019). Speeding of oxygen uptake kinetics is not different following low-intensity blood-flow-restricted and high-intensity interval training. Experimental physiology, 104(12), 1858-1867.

Credeur, D. P., Hollis, B. C. ve Welsch, M. A. (2010). Effects of handgrip training with venous restriction on brachial artery vasodilation. Medicine and science in sports and exercise, 42(7), 1296.

Cristina-Oliveira, M., Meireles, K., Spranger, M. D., O'Leary, D. S., Roschel, H. ve Peçanha, T. (2020). Clinical safety of blood flow-restricted training? A comprehensive review of altered muscle metaboreflex in cardiovascular disease during ischemic exercise. American Journal of Physiology-Heart and Circulatory Physiology, 318(1), H90-H109.

de Oliveira, M. F. M. d., Caputo, F., Corvino, R. B. ve Denadai, B. S. (2016). Shortterm low-intensity blood flow restricted interval training improves both aerobic fitness and muscle strength. Scandinavian journal of medicine ve science in sports, 26(9), 1017-1025.

Egan, B., O'connor, P. L., Zierath, J. R. ve O'gorman, D. J. (2013). Time course analysis reveals gene-specific transcript and protein kinetics of adaptation to short-term aerobic exercise training in human skeletal muscle. PloS one, 8(9), e74098.

Enoka, R. M. (1988). Muscle strength and its development. Sports Medicine, 6(3), 146-168.

Esbjörnsson, M., Jansson, E., Sundberg, C., Sylven, C., Eiken, O., Nygren, A. ve Kaijser, L. (1993). Muscle fibre types and enzyme activities after training with local leg ischaemia in man. Acta Physiologica Scandinavica, 148(3), 233-242.

Ferguson, R. A., Hunt, J. E., Lewis, M. P., Martin, N. R., Player, D. J., Stangier, C., . . . Turner, M. C. (2018). The acute angiogenic signalling response to low-load resistance exercise with blood flow restriction. European journal of sport science, 18(3), 397-406.

Gifford, J. R., Garten, R. S., Nelson, A. D., Trinity, J. D., Layec, G., Witman, M. A., . . . Etheredge, C. (2016). Symmorphosis and skeletal muscle: in vivo and in vitro measures reveal differing constraints in the exercise-trained and untrained human. The Journal of physiology, 594(6), 1741-1751. 
Groennebaek, T., Jespersen, N. R., Jakobsgaard, J. E., Sieljacks, P., Wang, J., Rindom, E., . . . Miller, B. F. (2018). Skeletal muscle mitochondrial protein synthesis and respiration increase with low-load blood flow restricted as well as high-load resistance training. Frontiers in physiology, 9, 1796.

Grønfeldt, B. M., Lindberg Nielsen, J., Mieritz, R. M., Lund, H. ve Aagaard, P. (2020). Effect of blood-flow restricted vs heavy-load strength training on muscle strength: Systematic review and meta-analysis. Scandinavian journal of medicine ve science in sports, 30(5), 837-848.

Gustafsson, T., Puntschart, A., Kaijser, L., Jansson, E. ve Sundberg, C. J. (1999). Exercise-induced expression of angiogenesis-related transcription and growth factors in human skeletal muscle. American Journal of Physiology-Heart and Circulatory Physiology, 276(2), H679-H685.

Gülfirat, Ö. ve Bişgin, H. (2021). BLOOD FLOW RESTRICTION IN STRENGTH TRAINING. European Journal of Physical Education and Sport Science, 6(11).

Hansen, S. K., Ratzer, J., Nielsen, J. L., Suetta, C., Karlsen, A., Kvorning, T., . . . Aagaard, P. (2020). Effects of alternating blood flow restricted training and heavy-load resistance training on myofiber morphology and mechanical muscle function. Journal of applied physiology, 128(6), 1523-1532.

Hellsten, Y. ve Nyberg, M. (2011). Cardiovascular adaptations to exercise training. Comprehensive Physiology, 6(1), 1-32.

Hostrup, M. ve Bangsbo, J. (2017). Limitations in intense exercise performance of athletes-effect of speed endurance training on ion handling and fatigue development. The Journal of physiology, 595(9), 2897-2913.

Hunt, J. E., Galea, D., Tufft, G., Bunce, D. ve Ferguson, R. A. (2013). Time course of regional vascular adaptations to low load resistance training with blood flow restriction. Journal of applied physiology, 115(3), 403-411.

Hunt, J. E., Walton, L. A. ve Ferguson, R. A. (2012). Brachial artery modifications to blood flow-restricted handgrip training and detraining. Journal of applied physiology, 112(6), 956-961.

Jones, H., Nyakayiru, J., Bailey, T. G., Green, D. J., Cable, N. T., Sprung, V. S., . . . Thijssen, D. H. (2015). Impact of eight weeks of repeated ischaemic preconditioning on brachial artery and cutaneous microcirculatory function in healthy males. European Journal of Preventive Cardiology, 22(8), 1083-1087. 
Yılmaz, D.A., ve Dege, G. (2021). Sporcularda Kan Akımı Kısıtlamalı Antrenman ve Fizyolojik Mekanizması. Gaziantep Üniversitesi Spor Bilimleri Dergisi, 6(3), 245-265.

Larsen, F. J., Schiffer, T. A., Zinner, C., Willis, S. J., Morales-Alamo, D., Calbet, J. A., ... Holmberg, H. C. (2020). Mitochondrial oxygen affinity increases after sprint interval training and is related to the improvement in peak oxygen uptake. Acta physiologica, 229(3), e13463.

Laursen, P. B. (2010). Training for intense exercise performance: high-intensity or high-volume training? Scandinavian journal of medicine ve science in sports, 20, 1-10.

Lignell, E., Fransson, D., Krustrup, P. ve Mohr, M. (2018). Analysis of high-intensity skating in top-class ice hockey match-play in relation to training status and muscle damage. The Journal of Strength ve Conditioning Research, 32(5), 1303-1310.

Lixandrao, M. E., Ugrinowitsch, C., Berton, R., Vechin, F. C., Conceição, M. S., Damas, F., . . . Roschel, H. (2018). Magnitude of muscle strength and mass adaptations between high-load resistance training versus low-load resistance training associated with blood-flow restriction: a systematic review and metaanalysis. Sports Medicine, 48(2), 361-378.

Loenneke, J. P., Wilson, J. M., Marín, P. J., Zourdos, M. C. ve Bemben, M. G. (2012). Low intensity blood flow restriction training: a meta-analysis. European journal of applied physiology, 112(5), 1849-1859.

Luebbers, P. E., Fry, A. C., Kriley, L. M. ve Butler, M. S. (2014). The effects of a 7week practical blood flow restriction program on well-trained collegiate athletes. The Journal of Strength ve Conditioning Research, 28(8), 2270-2280.

Manimmanakorn, A., Hamlin, M. J., Ross, J. J., Taylor, R. ve Manimmanakorn, N. (2013). Effects of low-load resistance training combined with blood flow restriction or hypoxia on muscle function and performance in netball athletes. Journal of science and medicine in sport, 16(4), 337-342.

Meinild Lundby, A. K., Jacobs, R., Gehrig, S., De Leur, J., Hauser, M., Bonne, T. C., . . . Kaech, A. (2018). Exercise training increases skeletal muscle mitochondrial volume density by enlargement of existing mitochondria and not de novo biogenesis. Acta physiologica, 222(1), e12905.

Mitchell, E. A., Martin, N. R., Turner, M. C., Taylor, C. W. ve Ferguson, R. A. (2019). The combined effect of sprint interval training and postexercise blood flow restriction on critical power, capillary growth, and mitochondrial proteins in trained cyclists. Journal of applied physiology, 126(1), 51-59. 
Morgan, N., Daniels, W. ve Subramaney, U. (2019). A prospective observational study of heroin users in Johannesburg, South Africa: Assessing psychiatric comorbidities and treatment outcomes. Comprehensive psychiatry, 95, 152137.

Mouser, J. G., Laurentino, G. C., Dankel, S. J., Buckner, S. L., Jessee, M. B., Counts, B. R., . . L Loenneke, J. P. (2017). Blood flow in humans following lowload exercise with and without blood flow restriction. Applied Physiology, Nutrition, and Metabolism, 42(11), 1165-1171.

Narici, M., Franchi, M. ve Maganaris, C. (2016). Muscle structural assembly and functional consequences. Journal of Experimental Biology, 219(2), 276-284.

Nielsen, J. L., Frandsen, U., Jensen, K. Y., Prokhorova, T. A., Dalgaard, L. B., Bech, R. D., . . . Aagaard, P. (2020). Skeletal Muscle Microvascular Changes in Response to Short-Term Blood Flow Restricted Training-Exercise-Induced Adaptations and Signs of Perivascular Stress. Frontiers in physiology, 11.

Nuzzo, J. L., Finn, H. T. ve Herbert, R. D. (2019). Causal mediation analysis could resolve whether training-induced increases in muscle strength are mediated by muscle hypertrophy. Sports Medicine, 49(9), 1309-1315.

Nyakayiru, J., Fuchs, C. J., Trommelen, J., Smeets, J. S., Senden, J. M., Gijsen, A. P., . . . Verdijk, L. B. (2019). Blood flow restriction only increases myofibrillar protein synthesis with exercise. Medicine and science in sports and exercise, 51(6), 1137.

Ozaki, H., Kakigi, R., Kobayashi, H., Loenneke, J., Abe, T. ve Naito, H. (2014). Effects of walking combined with restricted leg blood flow on $\mathrm{m}$ TOR and MAPK signalling in young men. Acta physiologica, 211(1), 97-106.

Pignanelli, C., Petrick, H. L., Keyvani, F., Heigenhauser, G. J., Quadrilatero, J., Holloway, G. P. ve Burr, J. F. (2020). Low-load resistance training to task failure with and without blood flow restriction: muscular functional and structural adaptations. American Journal of Physiology-Regulatory, Integrative and Comparative Physiology, 318(2), R284-R295.

Poole, D. C., Behnke, B. J. ve Musch, T. I. (2021). The role of vascular function on exercise capacity in health and disease. The Journal of physiology, 599(3), 889-910.

Preobrazenski, N., Islam, H., Drouin, P. J., Bonafiglia, J. T., Tschakovsky, M. E. ve Gurd, B. J. (2020). A novel gravity-induced blood flow restriction model 
Yılmaz, D.A., ve Dege, G. (2021). Sporcularda Kan Akımı Kısıtlamalı Antrenman ve Fizyolojik Mekanizması. Gaziantep Üniversitesi Spor Bilimleri Dergisi, 6(3), 245-265.

augments ACC phosphorylation and PGC-1a mRNA in human skeletal muscle following aerobic exercise: a randomized crossover study. Applied Physiology, Nutrition, and Metabolism, 45(6), 641-649.

Renzi, C. P., Tanaka, H. ve Sugawara, J. (2010). Effects of leg blood flow restriction during walking on cardiovascular function. Medicine and science in sports and exercise, 42(4), 726.

SA, H. K., Kianigul, M., Haghighi, A.-H., Nooghabi, M. J. ve Scott, B. R. (2020). Performing Soccer-Specific Training With Blood Flow Restriction Enhances Physical Capacities in Youth Soccer Players. Journal of Strength and Conditioning Research.

Scott, B. R., Loenneke, J. P., Slattery, K. M. ve Dascombe, B. J. (2016). Blood flow restricted exercise for athletes: A review of available evidence. Journal of science and medicine in sport, 19(5), 360-367.

Scott, B. R., Peiffer, J. J. ve Goods, P. S. (2017). The effects of supplementary lowload blood flow restriction training on morphological and performance-based adaptations in team sport athletes. The Journal of Strength ve Conditioning Research, 31(8), 2147-2154.

Sieljacks, P., Wang, J., Groennebaek, T., Rindom, E., Jakobsgaard, J. E., Herskind, J., . . . de Paoli, F. V. (2019). Six weeks of low-load blood flow restricted and high-load resistance exercise training produce similar increases in cumulative myofibrillar protein synthesis and ribosomal biogenesis in healthy males. Frontiers in physiology, 10, 649.

Skattebo, Ø., Calbet, J. A., Rud, B., Capelli, C. ve Hallén, J. (2020). Contribution of oxygen extraction fraction to maximal oxygen uptake in healthy young men. Acta Physiologica (Oxford, England), 230(2).

Suchomel, T. J., Nimphius, S. ve Stone, M. H. (2016). The importance of muscular strength in athletic performance. Sports Medicine, 46(10), 1419-1449.

Taylor, A. F., Saunders, M. M., Shingle, D. L., Cimbala, J. M., Zhou, Z. ve Donahue, H. J. (2007). Mechanically stimulated osteocytes regulate osteoblastic activity via gap junctions. American Journal of Physiology-Cell Physiology, 292(1), C545-C552.

Taylor, C. W., Ingham, S. A. ve Ferguson, R. A. (2016). Acute and chronic effect of sprint interval training combined with postexercise blood-flow restriction in trained individuals. Experimental physiology, 101(1), 143-154. 
Tinken, T. M., Thijssen, D. H., Hopkins, N., Dawson, E. A., Cable, N. T. ve Green, D. J. (2010). Shear stress mediates endothelial adaptations to exercise training in humans. Hypertension, 55(2), 312-318.

Vigotsky, A. D., Halperin, I., Lehman, G. J., Trajano, G. S. ve Vieira, T. M. (2018). Interpreting signal amplitudes in surface electromyography studies in sport and rehabilitation sciences. Frontiers in physiology, 8, 985.

Wernbom, M., Schoenfeld, B. J., Paulsen, G., Bjørnsen, T., Cumming, K. T., Aagaard, P., . . . Raastad, T. (2020). Commentary: can blood flow restricted exercise cause muscle damage? Commentary on blood flow restriction exercise: considerations of methodology, application, and safety. Frontiers in physiology, 11.

Wortman, R. J., Brown, S. M., Savage-Elliott, I., Finley, Z. J. ve Mulcahey, M. K. (2020). Blood Flow Restriction Training for Athletes: A Systematic Review. The American Journal of Sports Medicine, 0363546520964454. 